\title{
Numerical study of effect of cooling channel configuration and size on the product cooling effectiveness in the plastic injection molding
}

\author{
Angger Bagus Prasetiyo ${ }^{1}$, and Fauzun Fauzun ${ }^{1, *}$ \\ ${ }^{1}$ Universitas Gadjah Mada, Department of Mechanical and Industrial Engineering, Yogyakarta, Indonesia
}

\begin{abstract}
Injection molding is most frequently used manufacturing processes in the plastics industry. In the plastic injection molding process the cooling channel has an important role for the cooling process of the product. The good cooling channel is indicated by the ability to absorb heat from the product quickly and uniformly on the each side of the product. This study compared straight and conformal cooling channels with diameters $8 \mathrm{~mm}$ to know it is effects on pattern of temperature distribution in the mold and cooling effectiveness of the product inside mold using Fluent software. Analysis of virtual model images shown that those with conformal cooling channels can predict significant heat absorption compared with straight cooling channel.
\end{abstract}

\section{Introduction}

Injection molding widely used in plastic manufacturing process because it has the ability to mass-produce and quickly [1]. In the cycle of product-making process with injection molding there are three main phases, the first phase is the need to fill the mold cavity with liquid polymer (injection / filling step), and then the second phase is adding plastic material to the desired weight by using a liquid polymer (packing step), and then the third phase is the decrease temperature ejection (cooling phase). The third phase or cooling process in the product manufacturing cycle takes the longest time, as shown in Figure 1 .

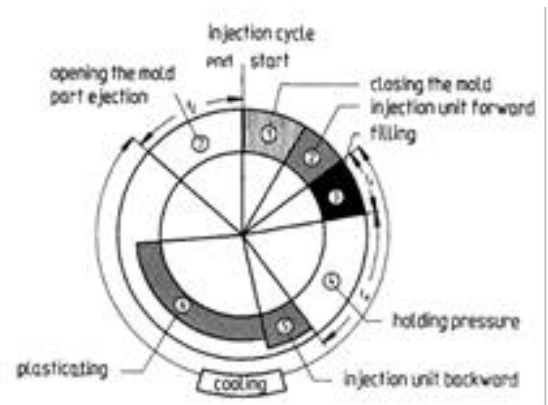

Fig. 1. Cycle of product manufacturing process in injection molding [2].

Some of the problems to be solved in the plastic forming process by using this injection molding method were cooling system optimization, on plastic molding in improving product quality and efficiency in production process where more than $17 \%$ plastic injection cycle was used for cooling stage [3]. More than 70 to $80 \%$ of this cooling stage was ble to reduce cooling time and improve production processes in injection molding molding process [4]. The cooling stage was the most influential stage because it determines the level at which parts were produced and their quality [5] to make the cooling process more efficient and there was a defect in the product, then the cooling system should be designed as possible.)

The research was to obtain such mathematical correlation by processing fluent simulation result using simple mathematic operation for simplification and statistical method for optimization [6]. ABM Saifullah and SH Masood cooling time effects and analyzed thermal using ANSYS 2007 software [7]. In 2009, the same group used the MPI simulation for analysis and compared the results for the conventional and conformal cooling sections and concluded conformal channels making the cooling time $35 \%$ less than the conventional ones [8]. The relationship between the 4 parameters for conformal cooling channel design using a manufacturing additive was discovered [9]. Several studies are currently underway in the analysis of various long-distance cooling channels for molding devices [10]. The use of different sections allows better cooling efficiency [11]. Then in 2017 Trade-off techniques and Design of Experiments (DOE) techniques was to used obtain optimum design configuration of conformal cooling channels for mechanical thermal mold performance [12].

This research was used to examine about the extentd of the effect of straight and conformal cooling system with $8 \mathrm{~mm}$ diameter in mold to the effectiveness of plastic product on injection mold. The optimal cooling system can produce a uniform gradient temperatures and will affect the yield product.

\footnotetext{
* Corresponding author: fauzun71@ugm.ac.id
} 


\section{Methodology}

\subsection{Material}

The case was a box product, the design has been carried out using 3D images are then stored in *iges format to be processed with ANSYS Fluent, with dimensions of size $160 \times 65 \times 70 \mathrm{~mm}$ made of polypropylene material. Figure 2 is an illustration of the product used. The distance cooling channel to the product and distance of each channel is $20 \mathrm{~mm}$. The possible result of distance in the mold gives better cooling performance for injection molding process.

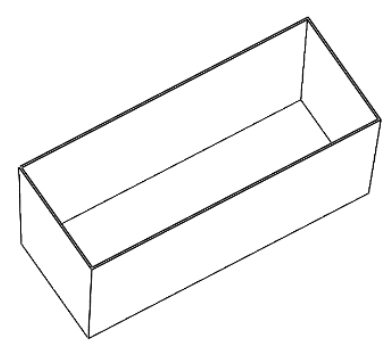

Fig. 2. The illustration of the product.

The thermal and physical properties of the polypropylene material, tool and coolant are as follows:

- Product (Polypropylene) properties (Fluent., Inc 2011)

Density

$1.7 \mathrm{~kg} / \mathrm{m}^{3}$

Specific heat capacity

$1441 \mathrm{~J} / \mathrm{kg} . \mathrm{K}$

Thermal conductivity

$0.0168 \mathrm{~W} / \mathrm{m} . \mathrm{K}$

- Tool (steel properties) (Fluent Inc., 2011):

Density $8030 \mathrm{~kg} / \mathrm{m}^{3}$

Specific heat capacity $502.48 \mathrm{~J} / \mathrm{kg} . \mathrm{K}$

Thermal conductivity $16.27 \mathrm{~W} / \mathrm{m} . \mathrm{K}$

- Coolant (water properties) ( Fluent Inc., 2011):

Density $998.2 \mathrm{~kg} / \mathrm{m}^{3}$

Specific heat capacity

$4182 \mathrm{~J} / \mathrm{kg} . \mathrm{K}$

Thermal conductivity

$0.6 \mathrm{~W} / \mathrm{m} . \mathrm{K}$

\subsection{General cooling channel design}

Cooling channels were created to cool the mold and reduce product defects. There are several alternative cooling system applications, such as cooling system without using fluid, straight channel and conformal channel. The cooling system did not use the liquid, have simpler manufacturing process but its heat transfer process takes a long time and lowers productivity level. Straight cooling channels can absorb heat effectively and cool down faster. However, the temperature and rate of heat transfer are not uniform. Conformal cooling can accelerate cooling time and heat distribution is relatively uniform resulting in good product quality, but manufacturing process was very complex. In addition, the number of channels, coolant distances and diameter of channel have an effect in the cooling process of the mold.

\subsection{Straight cooling channel design}

The straight cooling channel was generated outside surface of the mould with hallow passageway of coolant inside the mold.The channel of cooling system were designed with circular-cross section and $8 \mathrm{~mm}$ diameter according to the standard design. as shown in Fig. 3.

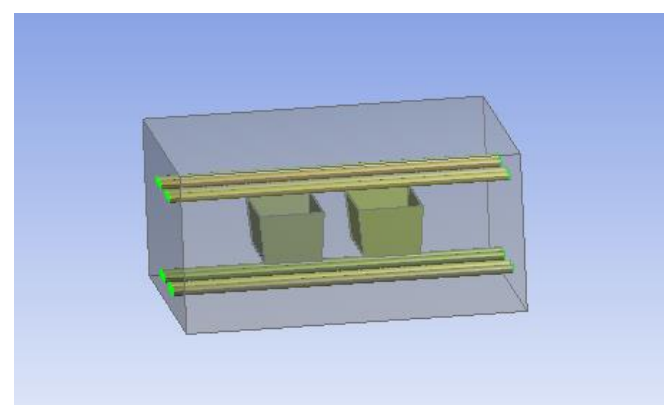

Fig. 3. Design straight cooling channel.

\subsection{Design conformal cooling channel}

The conformal cooling channel system was generated inside and exterior surface mold to the surface product. The connectivity of cooling channel both are same to flow of inlet and outlet the part, as shown in Fig. 4.

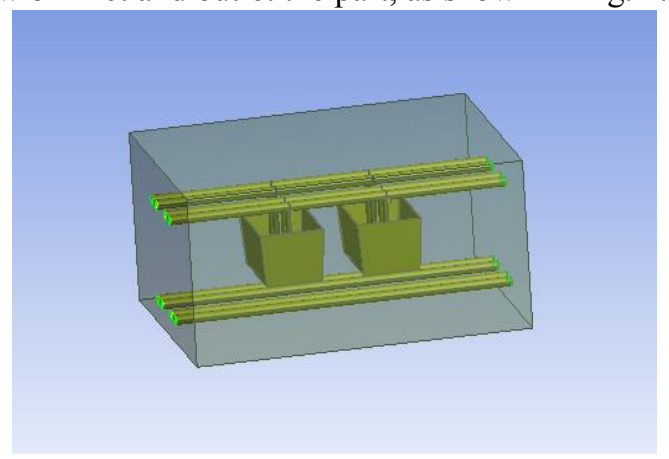

Fig. 4. Design conformal cooling channel.

\subsection{Modeling}

To simplify the simulation problem, the analyzed area was limited to cavity plate, product and core plate, with straight cooling channel and conformal cooling channel with a diameter $8 \mathrm{~mm}$, with the consideration that the significant heat transfer occurs only in that section, while on the other part was considered not to give a significant effect.

The following steps were performed for each variant of the simulation :

1) Pre processing and problem identification

- Defines the purpose of modeling

- Identifying of the domain model

- Designed and created a gird of the model

- Determine the boundary type and the continuum

- $\quad$ Exporting the file to a *msh file 
2) Solver execution

- Import the *msh file

- Setting a numerical model

- Compute and monitor the solution

3) Post-processing

- Examining of the result

- Considering revision of the model

\section{Results and discussion}

After analysis, the diameter cooling channel was around $8 \mathrm{~mm}$, distance cooling channel to the product and distance of each channel is $20 \mathrm{~mm}$. Such parameters are chosen because they are often used in the plastics industry. From the simulation results using ansys fluent then get result as in figure 5 .

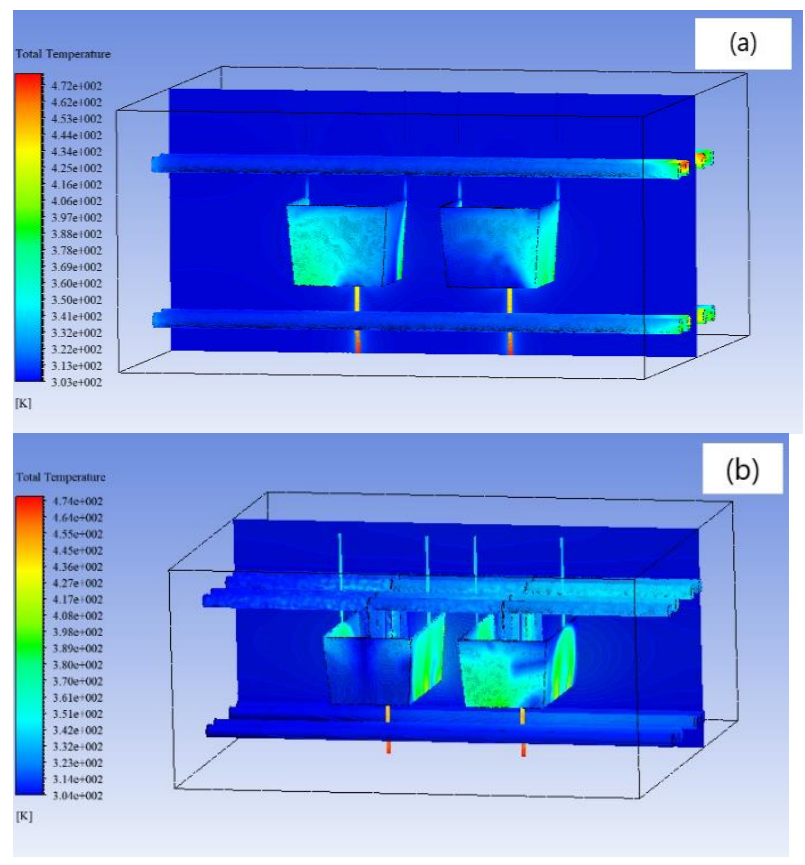

Fig. 5. Contours of the temperature distribution : (a) conformal cooling channel, (b) straight cooling channel.

Fig. 5 shows the contours distribution temperature. Fig. 5 (a) shows the contours distribution temperature of the wall on straight cooling channel. while the fig. 5 (b) shown the contours distribution temperature of the wall on conformal cooling channel.

The results shown in Figure 5 (a) and 5 (b), explains the contours of heat absorption temperature in the cooling system, the contour is shown to see how much heat is absorbed by the fluid at the outlet. The greatest heat in straight cooling channel is part out, because all heat absorbed the fluid will accumulate on the part so that contours on the outlet is red. while for conformal cooling channels, the largest heat absorption is the channel portion close to the product. It is shown with the contours are red, while on the outlet contours are not red, it indicates that there has been a decrease in temperature, the decline is due to the heat carried by the fluid has spread to the mold so that the heat in the outlet becomes reduced.

In addition to the figure of contour, this research also presents a grapgh of the temperature compression and pressure cooling ratio as shown in Fig. 6(a) and 6(b).

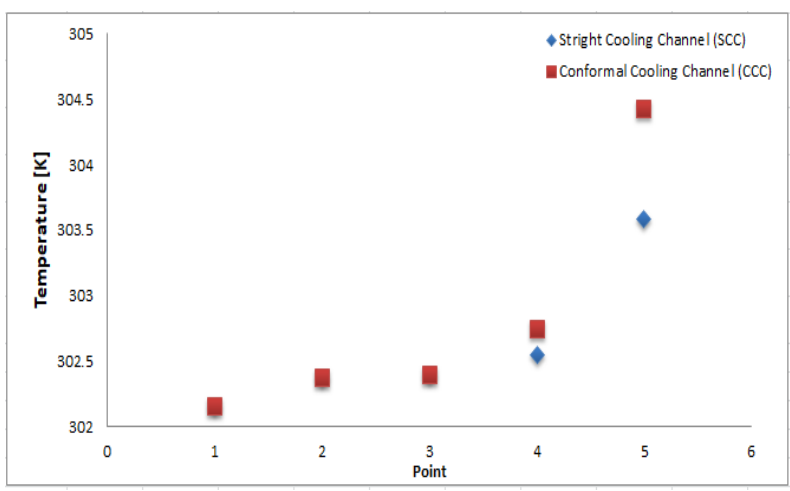

Fig. 6a. Heat absorption of each channels.

From Fig. 6(a) it can be shown that conformal cooling channels provide better heat absorption than conventional channels. To determine the temperature of heat absorption by taking at 5 point section on each cooling channel. this do it because on the part of each channel has a different temperature distribution.

From Fig. 6(a) the temperature for a straight cooling channel has been found at around $303,589^{\circ} \mathrm{C}$ and for a conformal cooling channel it was about $304.429^{\circ} \mathrm{C}$. So it can be predicted that $2{ }^{\circ} \mathrm{C}$ product temperature can be reduced by applying a conformal cooling channel.

Fig. 6(b) Shown that the conformal cooling channel has a significant pressure drop compared to the straight cooling channel. it is due to the fluid friction force with the channel wall, the difference in channel shape and channel length. 5 points taken on each cooling channel, this do it because on the part of each channel has a different pressure drop.

Fig. 6(b) the pressure for the straight cooling channel has been found around $524562 \mathrm{~Pa}$ and conformal cooling channels was about around 17428.2 Pa.

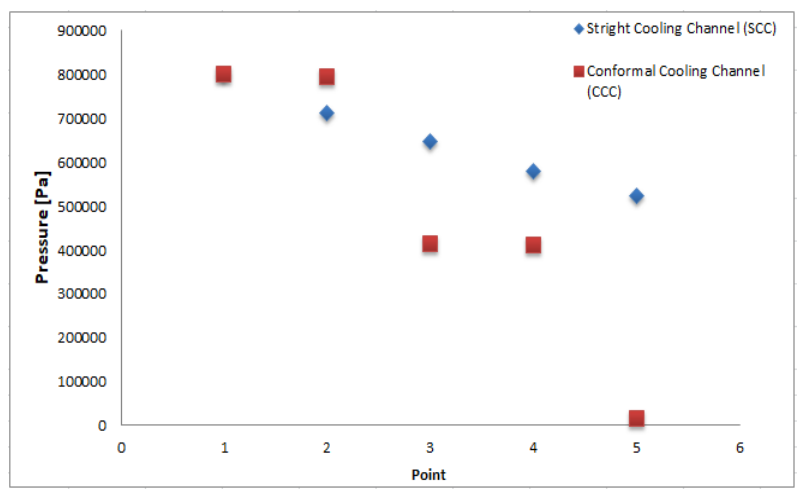

Fig. 6(b). Pressure drop of each channels.

\section{Conclusions}

The cooling process accounts for about $75 \%$ to $85 \%$ of the total cycle time and its effects directly the shrinkage 
bend and warpage. Therefore, designed a good system was crutial to affect the production rate and quality. The results were shown that with proper geometry and layout, the cooling system has a heat absorbtion of $2^{\circ}$ $\mathrm{C}$, and more effectively to cool the product. In this research, the analysis result were shown from cooling system but the temperature on product were not shown.

The authors are also grateful to the staff of PT. ATMI Surakarta and staff Laboratory of Heat Transfer and Mass, Department of Mechanical and Industrial Engineering, Faculty of Engineering, Universitas Gadjah Mada.

\section{References}

1. D.V. Rosato, M.G. Rosato, Injection Molding Handbook 3rd ed. (Norwell: Kluwer Academic Publishers, 2012)

2. G. Pötsch, W. Michaeli, Injection Molding an Introduction (Hanser Verlag, 2008)

3. L.Q. Tang, C. Chassapis, S. Manaachehri, "Optimal Cooling System Design for Multy Cavity Injection Molding," Jurnal of Fenite Elements in Analysis and Design 26, 229-251 (1997)

4. L.W. Seow, Y.C. Lam, "Optimizing Flow In Plastic Injection Molding," J. mater process technol 72 (3), 333-341(1997)

5. E. Sachs, E. Wylonis, S. Allen, M. Cima, H. Guo, "Production of injection Molding Tooling with Conformal Cooling Channels Using the three Dimensional Printing Process," Polymer Engineering \& Science 40, 1232-1247 (2000)

6. Fauzun, M. Hamdi, A.E. Tantowi, T. Ariga, "Formulation of the Size and Position of Spiral Cooling Channel in Plastic Injection Mold Based of Fluent Simulation Results," Proceedings of the 2008 IEEE IEEM (2008)

7. A. Saifullah, S. Masood, "Finite Element Thermal Analysis of Conformal Cooling Channels in Injection Molding," Proceedings of the 5th Australasian congress on applied mechanics. Engineers Australia 337 (2007)

8. A. Saifullah, S. Masood, I. Sbarski, "New cooling channel design for injection molding," Proceedings of the World Congress on Engineering (2009)

9. S. Mayer, "Optimised mold temperature control procedure using DMLS,” EOS (2005)

10. K. Au, K. Yu, "Variable Distance Adjustment for Conformal Cooling Channel Design in Rapid Tool," Journal of Manufacturing Science and Engineering 136, 044501 (2014)

11. Suchana A. Jahan, Hazim El-Mounayri, Optimal Conformal Cooling Channels in 3D Printed Dies for Plastic Injection Molding. 5, 888-900 (2016)

12. Suchana A. Jahan, Tong Wu, Yi Zhang, Jing Zhang, Andres Tovar, Hazim Elmounayri, "ThermoMechanical Design Optimization of Conformal Cooling Channels Using Design of Experiments
Approach," Procedia Manufacturing 10, 898 - 911 (2017) 